Supporting Information

\title{
Conversion of Beech Wood into Antiviral Lignin-Carbohydrate Complexes by Microwave Acidolysis
}

Ruibo Li $^{1}$, Ryota Ouda ${ }^{1,2}$, Chihiro Kimura ${ }^{1}$, Ryo Narita ${ }^{1,2}$, Hiroshi Nishimura ${ }^{1}$, Takashi Fujita ${ }^{2}$, Takashi Watanabe ${ }^{1^{*}}$

1. Laboratory of Biomass Conversion, Research Institute for Sustainable Humanosphere, Uji

Campus, Kyoto University, Gokasho, Uji, Kyoto, 611-0011, Japan

2. Laboratory of Molecular Genetics, Institute for Frontier Life and Medical Sciences, Kyoto University, Shogoin, Kawahara-Cho, Sakyo-Ku, Kyoto, 606-8507, Japan

${ }^{*}$ Corresponding author. Tel: +81-774-38-4640. Fax: +81-774-38-3681.

E-mail: twatanab@rish.kyoto-u.ac.jp

(This document contains 14 pages, 2 tables, 6 figures) 
Preparation of Milled Wood Lignin (MWL) from Beech. The wood meal from beech was extracted with a toluene and ethanol $(2: 1, \mathrm{v} / \mathrm{v})$ mixture using a Soxhlet extractor for $10 \mathrm{~h}$. The wood meal was dried at $105{ }^{\circ} \mathrm{C}$ for $12 \mathrm{~h}$ and finely divided in a vibratory ball mill for $48 \mathrm{~h}$ under a nitrogen atmosphere with constant cooling using running water. The wood meal was extracted with $96 \%$ aq. dioxane for $24 \mathrm{~h}$ at room temperature. The extract was evaporated and then freeze-dried. The crude MWL was dissolved in $90 \%$ aq. acetic acid and then precipitated from distilled water. The precipitates were dissolved in a 1,2-dichloroethane and ethanol $(2: 1, \mathrm{v} / \mathrm{v})$ mixture and added to diethyl ether. The precipitate was washed with petroleum ether and evaporated to give the MWL fractions. ${ }^{\mathrm{S} 1, \mathrm{~S} 2}$

Gel Permeation Chromatography (GPC). $2 \mathrm{mg}$ samples were acetylated with $1.0 \mathrm{~mL}$ of anhydrous pyridine and $1.0 \mathrm{~mL}$ of acetic anhydride, which were stirred at room temperature for 24 h, and dried by nitrogen gas. The acetylated samples were dissolved in tetrahydrofuran (THF), and filtered though a $0.45 \mu \mathrm{m}$ polytetrafluoroethylene (PTFE) filter. The samples were analyzed utilizing a Shimadzu instrument equipped with a SPD M20A diode array detector, a UV detector, and three $150 \mathrm{~mm} \times 4.6 \mathrm{~mm}$ i.d. $4.0 \mu \mathrm{m}$ TSK gel supermultipore HZ-M columns (Tosoh, Tokyo, Japan).

Polystyrene with different molecular weight $(2,110,000,427,000,37900$, and 5970), pinoresinol (MW352), and vanillin (MW 152) were used as standard sample to make a calibration curve, and the MW of fractions were calibrated by using this curve.

2D-HSQC NMR. HSQC NMR spectra were recorded at $40^{\circ} \mathrm{C}$ on a Bruker Avance III $600 \mathrm{MHz}$ instrument (Bruker BioSpin, Rheinstetten, Germany) equipped with a cryogenic probe. Each sample (approximately $80 \mathrm{mg}$ ) was dissolved in $0.5 \mathrm{~mL}$ of DMSO-d $\mathrm{d}_{6}$. For quantification of lignin interlinkages, $2.0 \mu \mathrm{mol}$ of sodium trimethylsilypropanesulfonate (DSS- $\mathrm{d}_{6}$ ) was added into each 
fraction, and used as an internal standard. Correlations signal from $\mathrm{C}_{\alpha} / \mathrm{H}_{\alpha}$ of $\beta$-O-4, $\alpha$-oxidized $\beta$ - $\beta$, and $\beta-5$ were applied for quantification. Relative amount of interlinkages were calculated by setting the integral of DSS as “1.0".

The central solvent peak (DMSO) at $\delta_{\mathrm{C} / \mathrm{H}} 39.5 / 2.49 \mathrm{ppm}$ was used as the reference. The HSQC experiment was conducted using Bruker's hsqcetgpsisp2.2 pulse program with spectral widths of 5000 and $27173 \mathrm{~Hz}$ for the ${ }^{1} \mathrm{H}$ and ${ }^{13} \mathrm{C}$ dimensions, respectively. The number of transients was 32 and 256 times increments in the ${ }^{13} \mathrm{C}$ dimension. The ${ }^{1} J_{\mathrm{CH}}$ was $145 \mathrm{~Hz}$. The data were processed using the Bruker Topspin 3.5 software.

Carbohydrate Analysis and Lignin Quantification. For carbohydrate analysis, neutral sugars in the fractions were degraded by hydrolysis in the presence of $72 \% \mathrm{H}_{2} \mathrm{SO}_{4}$ for $4 \mathrm{~h}$ at room temperature, followed by auto-clave hydrolysis at $121{ }^{\circ} \mathrm{C}$ for $1 \mathrm{~h}$ after dilution to $3 \% \mathrm{H}_{2} \mathrm{SO}_{4}$. Subsequently, the hydrolyzed solution was neutralized and centrifuged. The top clear layer was injected into the HPLC apparatus equipped with a post-column and a fluorometric detector (HPLC Prominence HPLC-system, Shimadzu, Co., Ltd, Kyoto, Japan). Two HPX-87P columns (Bio-Rad, CA, USA) were used for mono-sugar separation and the column oven was set at $42{ }^{\circ} \mathrm{C}$. The mono-sugar samples were labelled at $150{ }^{\circ} \mathrm{C}$ using an aqueous solution of L-arginine (1\%) and boric acid (3\%). The flow rate was set to $0.3 \mathrm{~mL} / \mathrm{min} .{ }^{\mathrm{S}}$

Klason lignin was determined by the weight ratio of the solid residue after two-step acid hydrolysis according to the TAPPI T222 om-98 procedure. The acid soluble lignin was evaluated utilizing a UV-vis spectrometer at $204 \mathrm{~nm}$ after 20 -fold dilution using $3 \% \mathrm{H}_{2} \mathrm{SO}_{4}$. $^{\mathrm{S}}$

Cell Culture. L929 cells (murine fibroblast cell line purchased from ATCC, Virgina, USA) were maintained in Eagle's minimum essential medium (MEM, Nacalai Tesque, Kyoto, Japan) supplemented with 5\% fetal bovine serum (BioWest, USA), $100 \mathrm{U} / \mathrm{mL}$ penicillin, and $100 \mu \mathrm{g} / \mathrm{mL}$ 
streptomycin (Nacalai Tesque, Kyoto, Japan). The cells were incubated at $37^{\circ} \mathrm{C}$ with $5.0 \% \mathrm{CO}_{2}$.

Virus Inactivation Assay. For the inactivation assay, $10 \mu \mathrm{L}$ of the medium (MEM) containing 1 $\times 10^{6} \mathrm{pfu}$ EMCV was incubated with a $10 \mu \mathrm{L}$ sample on ice for $1 \mathrm{~h}$. DMSO was used as the solvent control. $80 \mu \mathrm{L}$ of the culture medium was added to the mixture. Subsequently, $10 \mu \mathrm{L}$ of the mixture was added to $1 \mathrm{~mL}$ of the culture medium containing $2.5 \times 10^{5}$ L929 cells in a 12-well plate. After 6 $\mathrm{h}$ of incubation, the cells were harvested and subjected to quantitative real-time polymerase chain reaction (PCR) according to the method described in our previous report. The IC50 value was defined as the concentration at which a compound inactivated the relative EMCV RNA levels of the treated cells by $50 \%$. 
Table S1. Chemical Shift Assignment of ${ }^{13} \mathrm{C}-{ }^{1} \mathrm{H}$ Cross-signals in the HSQC Spectra of Fractions

\begin{tabular}{|c|c|c|}
\hline & $\delta_{\mathrm{C}} / \delta_{\mathrm{H}}$ & assignment \\
\hline $\mathrm{HK}_{\alpha}$ & $44.6 / 3.67$ & $\mathrm{C}_{\alpha}-\mathrm{H}_{\alpha}$ in Hibbert ketone $(\mathrm{HK})$ \\
\hline$-\mathrm{OCH}_{3}$ & $55.9 / 3.73$ & $\mathrm{C}-\mathrm{H}$ in methoxy group \\
\hline $\mathrm{A}_{\gamma}$ & $59.8 / 3,40$ and 3,75 & $\mathrm{C}_{\gamma}-\mathrm{H}_{\gamma}$ in $\beta-O-4$ substructures (A) \\
\hline $\mathrm{C}_{\gamma}$ & $62.5 / 3.72$ & $\mathrm{C}_{\gamma}-\mathrm{H}_{\gamma}$ in $\beta-5$ substructures $\left(\mathrm{C}^{\prime}\right)$ \\
\hline $\mathrm{HK}_{\gamma}$ & $67.5 / 4.15$ & $\mathrm{C}_{\gamma}-\mathrm{H}_{\gamma}$ in Hibbert ketone $(\mathrm{HK})$ \\
\hline $\mathrm{B}_{\gamma}$ & $71.2 / 3.85$ and 4.20 & $\mathrm{C}_{\gamma}-\mathrm{H}_{\gamma}$ in pinoresinol $\beta-\beta$ ' substructures (B) \\
\hline $\mathrm{A}_{\alpha}$ & $71.6 / 4.87$ & $\mathrm{C}_{\alpha}-\mathrm{H}_{\alpha}$ in $\beta-O-4$ substructures $(\mathrm{A})$ \\
\hline $\mathrm{BE}_{1}$ & $80.0-82.0 / 4.5-4.8$ & benzyl ether in primary $\mathrm{OH}$ of carbohydrate in $\mathrm{LCC}$ \\
\hline $\operatorname{Aox}_{\beta}$ & $83.3 / 5.26$ & $\mathrm{C}_{\beta}-\mathrm{H}_{\beta}$ in oxidized $\beta-O-4$ substructures (Aox) \\
\hline $\mathrm{A}_{\beta}(\mathrm{G} / \mathrm{H})$ & $83.6 / 4.33$ & $\mathrm{C}_{\beta}-\mathrm{H}_{\beta}$ in $\beta-O-4$ substructures linked to $\mathrm{G}$ unit (A) \\
\hline $\mathrm{B}_{\alpha}$ & $85.2 / 4.66$ & $\mathrm{C}_{\alpha}-\mathrm{H}_{\alpha}$ in pinoresinol $\beta-\beta$ ' substructures (B) \\
\hline $\mathrm{A}_{\beta}(\mathrm{S})$ & $86.0 / 4.16$ & $\mathrm{C}_{\beta}-\mathrm{H}_{\beta}$ in $\beta-O-4$ substructures linked to $\mathrm{S}$ unit (A) \\
\hline $\mathrm{C}_{\alpha}$ & $85.2 / 4.66$ & $\mathrm{C}_{\alpha}-\mathrm{H}_{\alpha}$ in $\beta-5$ substructures $(\mathrm{C})$ \\
\hline $\mathrm{G}_{2}$ & $110.3 / 6.93$ & $\mathrm{C}_{2}-\mathrm{H}_{2}$ in guaiacyl unit $(\mathrm{G})$ \\
\hline $\mathrm{G}_{5}$ & $\begin{array}{l}115.1 / 6.71 \text { and } \\
6.93\end{array}$ & $\mathrm{C}_{5}-\mathrm{H}_{5}$ in guaiacyl unit $(\mathrm{G})$ \\
\hline $\mathrm{G}_{2}^{\prime}$ & $111.7 / 7.53$ & $\mathrm{C}_{2}-\mathrm{H}_{2}$ in oxidized guaiacyl unit $\left(\mathrm{G}^{\prime}\right)$ \\
\hline $\mathrm{G}_{6}$ & $118.6 / 6.78$ & $\mathrm{C}_{6}-\mathrm{H}_{6}$ in guaiacyl unit $(\mathrm{G})$ \\
\hline $\mathrm{G}^{\prime}{ }_{6}$ & $123.2 / 7.61$ & $\mathrm{C}_{6}-\mathrm{H}_{6}$ in oxidized guaiacyl unit $\left(\mathrm{G}^{\prime}\right)$ \\
\hline $\mathrm{S}_{2,6}$ & $103.5 / 6.64$ & $\mathrm{C}_{2}-\mathrm{H}_{2}$ and $\mathrm{C}_{6}-\mathrm{H}_{6}$ in syringyl unit $(\mathrm{S})$ \\
\hline $\mathrm{S}{ }^{\prime}{ }_{2,6}$ & $107.2 / 7.21$ & $\begin{array}{l}\mathrm{C}_{2}-\mathrm{H}_{2} \text { and } \mathrm{C}_{6}-\mathrm{H}_{6} \text { in oxidized syringyl unit with a carboxyl } \\
\text { group at } \mathrm{C} \alpha\left(\mathrm{S}^{\prime \prime}\right)\end{array}$ \\
\hline $\mathrm{S}_{2,6}$ & $106.5 / 7.34$ & $\mathrm{C}_{2}-\mathrm{H}_{2}$ and $\mathrm{C}_{6}-\mathrm{H}_{6}$ in oxidized syringyl unit ( $\left.\mathrm{S}^{\prime}\right)$ \\
\hline $\mathrm{PB}_{2,6}$ & $131.2 / 7.66$ & $\mathrm{C}_{2}-\mathrm{H}_{2}$ and $\mathrm{C}_{6}-\mathrm{H}_{6}$ in $p$-benzoate unit $(\mathrm{PB})$ \\
\hline $\mathrm{G}_{2}$ and $\mathrm{G}_{5}$ in $\mathrm{HK}$ & $106.8 / 6.57$ & $\mathrm{C}_{2}-\mathrm{H}_{2}$ and $\mathrm{C}_{5}-\mathrm{H}_{5}$ in Hibbert ketone linked to $\mathrm{G}$ unit $(\mathrm{HK})$ \\
\hline $\mathrm{G}_{6}$ in $\mathrm{HK}$ & $118.6 / 6.78$ & $\mathrm{C}_{2}-\mathrm{H}_{2}$ in Hibbert ketone linked to $\mathrm{G}$ unit $(\mathrm{HK})$ \\
\hline
\end{tabular}




\begin{tabular}{|c|c|c|}
\hline $\mathrm{S}_{2,6}$ in $\mathrm{HK}$ & $106.8 / 6.57$ & $\mathrm{C}_{2}-\mathrm{H}_{2}$ and $\mathrm{C}_{6}-\mathrm{H}_{6}$ in Hibbert ketone linked to $\mathrm{S}$ unit $(\mathrm{HK})$ \\
\hline $\mathrm{Xyl}(\mathrm{r} \alpha)$ & $92.2 / 4.94$ & $\mathrm{C}_{1}-\mathrm{H}_{1}$ in $\alpha$-D-xylopyranoside of xylans reducing end \\
\hline $\mathrm{Xyl}(\mathrm{r} \beta)$ & $96.9 / 4.31$ & $\mathrm{C}_{1}-\mathrm{H}_{1}$ in $\beta$-D-xylopyranoside of xylans reducing end \\
\hline $\mathrm{Xyl}_{1}$ & $101.9 / 4.24$ & $\mathrm{C}_{1}-\mathrm{H}_{1}$ in $\beta$-D-xylopyranoside \\
\hline Xyl1(nr.int) & $103.3 / 4.15$ & $\begin{array}{l}\mathrm{C}_{1}-\mathrm{H}_{1} \text { in } \beta \text {-D-xylopyranoside of xylans internal } \\
\text { non-reducing units }\end{array}$ \\
\hline $\mathrm{Xyl}_{2}$ & $72.3 / 3.16$ & $\mathrm{C}_{2}-\mathrm{H}_{2}$ in $\beta$-D-xylopyranoside \\
\hline $\mathrm{Xyl}_{3}$ & $73.0 / 3.46$ & $\mathrm{C}_{3}-\mathrm{H}_{3}$ in $\beta$-D-xylopyranoside \\
\hline $\mathrm{Xyl}_{4}$ & $74.6 / 3.50$ & $\mathrm{C}_{4}-\mathrm{H}_{4}$ in $\beta$-D-xylopyranoside \\
\hline $\mathrm{Xyl}_{5}$ & $62.5 / 3.42$ and 3.72 & $\mathrm{C}_{5}-\mathrm{H}_{5}$ in $\beta$-D-xylopyranoside \\
\hline $\operatorname{Glc}(\mathrm{r} \alpha)$ & $92.2 / 4.94$ & $\mathrm{C}_{1}-\mathrm{H}_{1}$ in $\alpha$-D-glucopyranoside of glucans reducing end \\
\hline $\operatorname{Glc}(r \beta)$ & $96.9 / 4.30$ & $\mathrm{C}_{1}-\mathrm{H}_{1}$ in $\beta$-D-glucopyranoside of glucans reducing end \\
\hline $\mathrm{Glc}_{1}$ & $101.0 / 4.26$ & $\mathrm{C}_{1}-\mathrm{H}_{1}$ in $\beta$-D-glucopyranoside \\
\hline $\mathrm{Glc}_{2}$ & $74.9 / 2.93$ & $\mathrm{C}_{2}-\mathrm{H}_{2}$ in $\beta$-D-glucopyranoside \\
\hline $\mathrm{Glc}_{3}$ & $76.8 / 3.12$ & $\mathrm{C}_{3}-\mathrm{H}_{3}$ in $\beta$-D-glucopyranoside \\
\hline $\mathrm{Glc}_{5}$ & $70.5 / 3.08$ & $\mathrm{C}_{5}-\mathrm{H}_{5}$ in $\beta$-D-glucopyranoside \\
\hline
\end{tabular}




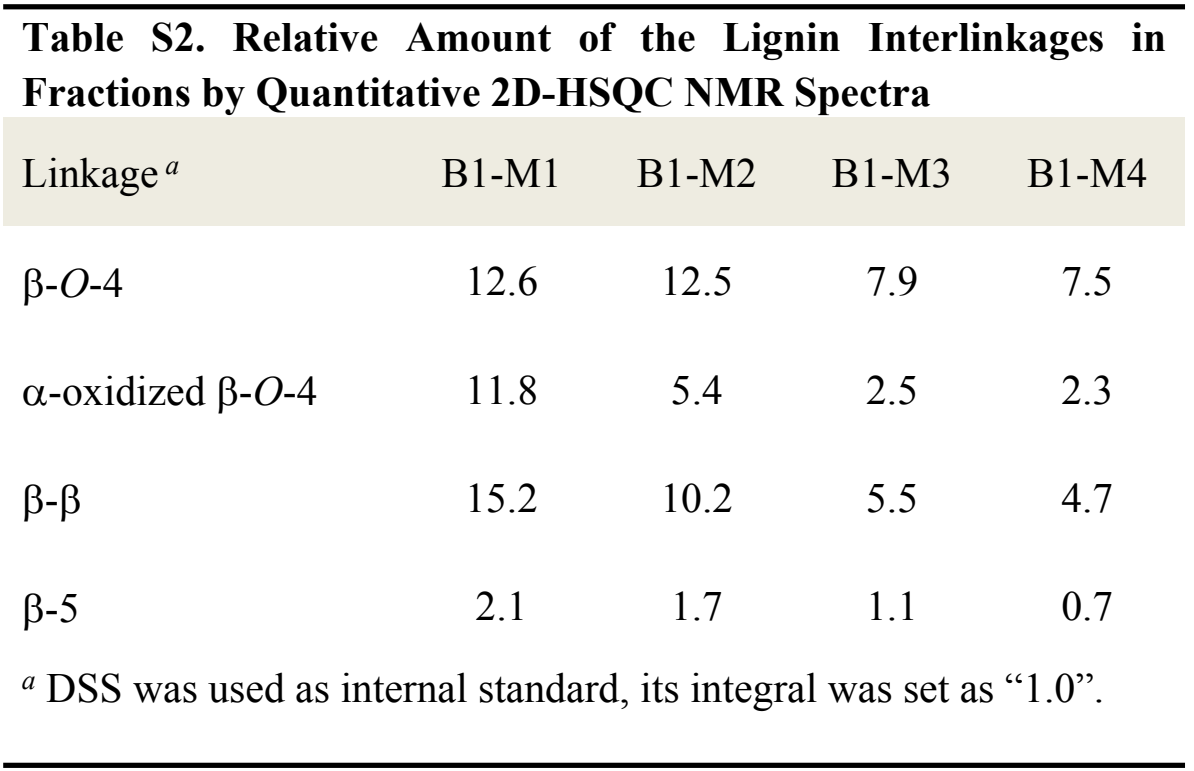




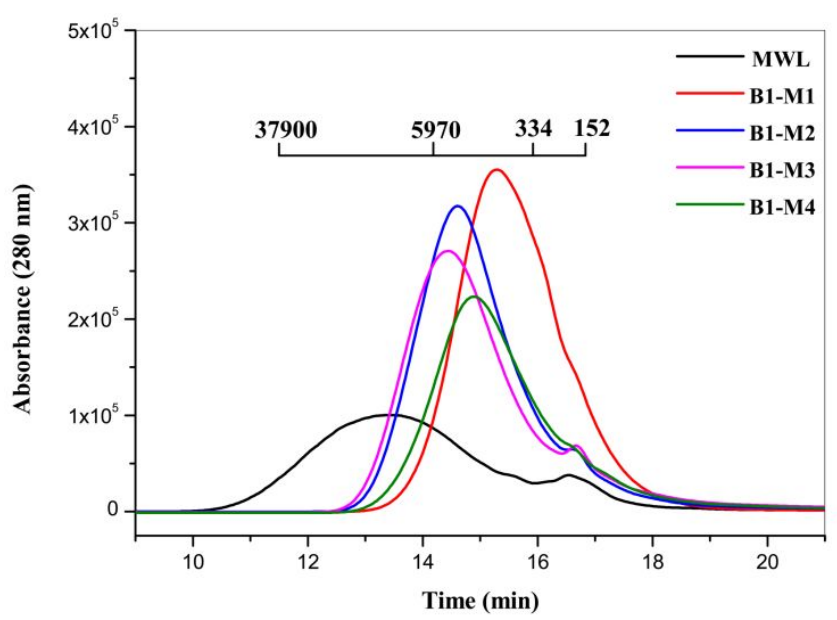

Figure S1. GPC chromatograms of MWL and the fractions separated from microwave acidolysis products from wood powder. 


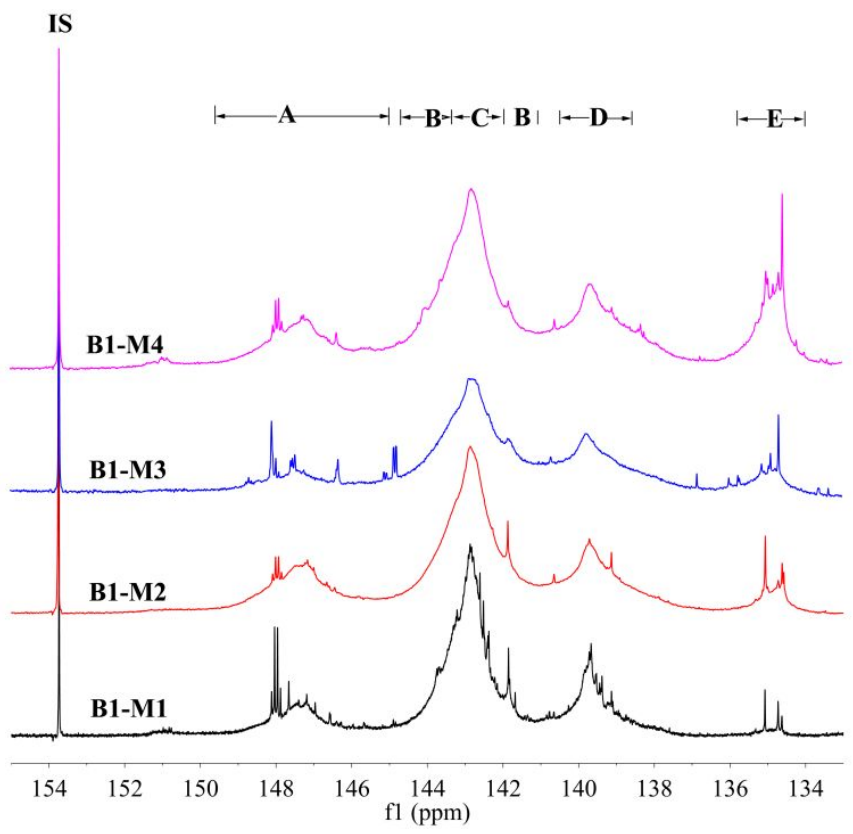

Figure S2. ${ }^{31} \mathrm{P}$ NMR spectra and signal assignments of fractions phosphitylated with TMDP. Chemical shift regions: A: 149.1-145.0 aliphatic OH, B: 144.6-143.3 and 142.0-141.2 condensed $\mathrm{OH}, \mathrm{C}$ : 143.3-142.0 syringyl phenolic OH, D: 140.5-138.6 guaiacyl phenolic OH, E: 135.9-134.0 carboxylic $\mathrm{OH}$. 


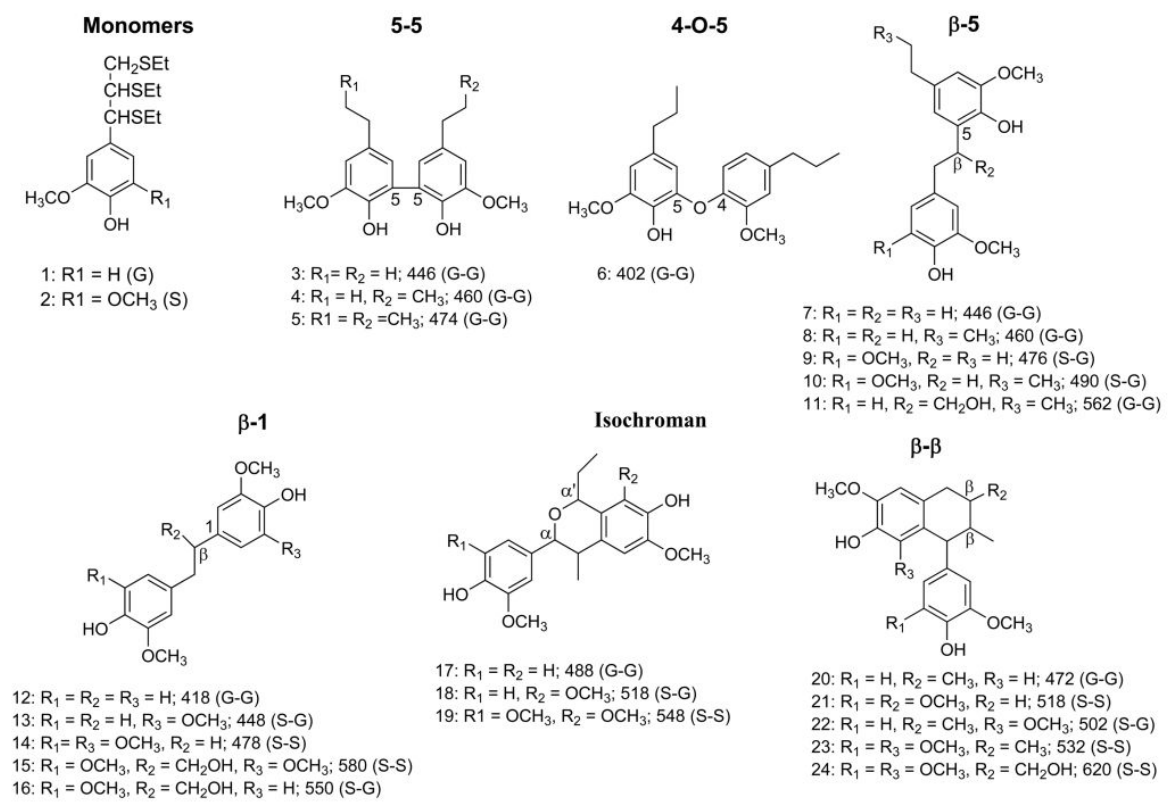

Figure S3. Structures of monomeric and main dimeric compounds obtained after thioacidolysis and Raney-nickel desulfurization of the fractions. 

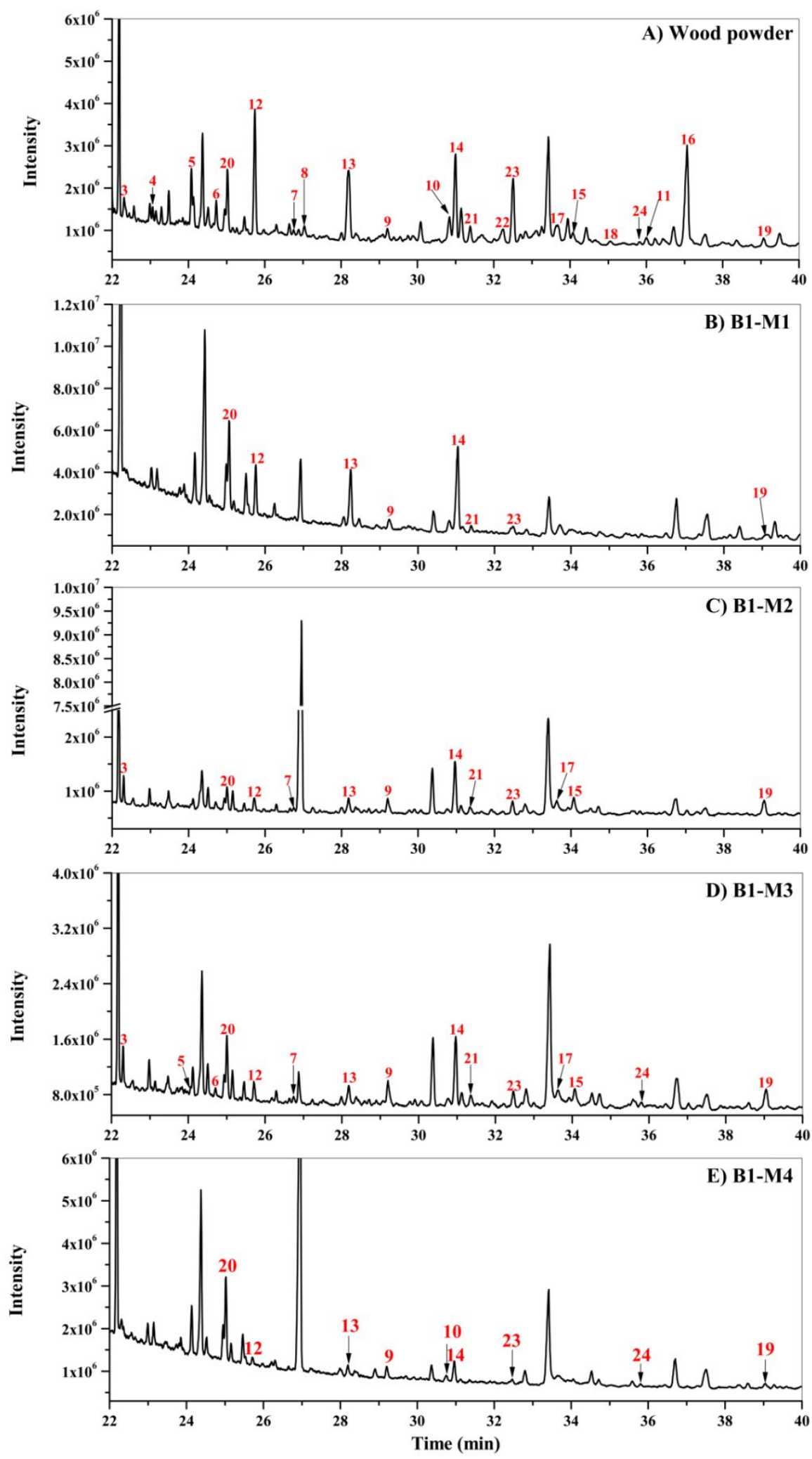

Figure S4. GC-MS total ion current chromatograms of the dimeric thioacidolysis products after Raney nickel desulfuration from fractions. The numbered peaks refer to the trimethysilylated derivatives of the compounds shown in Figure S3. 


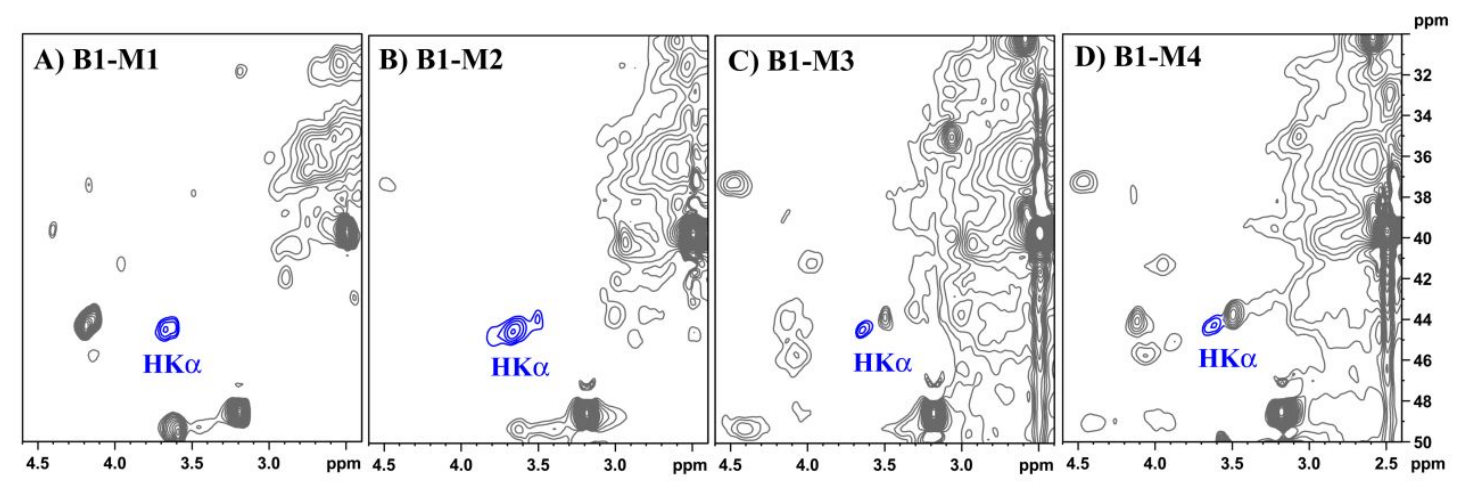

Figure S5. Correlation signal of $\mathrm{C} \alpha-\mathrm{H} \alpha$ in Hibbert ketone (HK) of fractions (A) B1-M1, (B) B1-M2, (C) B1-M3, and (D) B1-M4. 

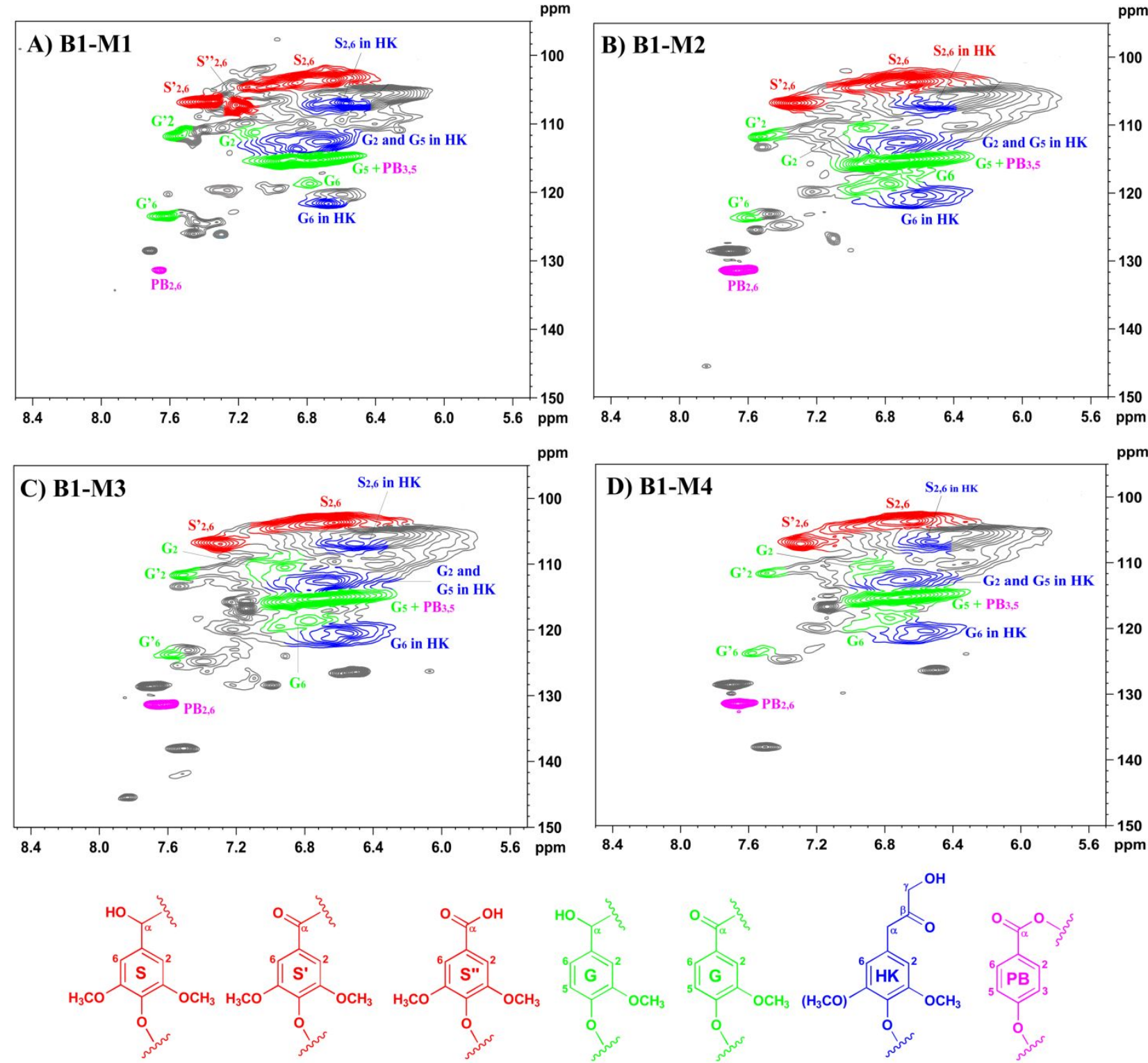

Figure S6. Aromatic region of 2D 13C-1H correlation (HSQC) spectra of fractions (A) B1-M1, (B) B1-M2, (C) B1-M3, and (D) B1-M4. Symbols are taken from Table S1.

\section{Reference}

(S1) Ohata. Y.; Hasegawa, R.; Kurosawa, K.; Maeda, A. H.; Koizumi, T.; Nishimura, H.; Okada, H.; Qu, C.; Saito, K.; Watanabe, T.; Hatada, Y. Enzymatic specific production and chemical functionalization of phenylpropanone platform monomers from lignin. ChemSusChem, 2017, $10(2), 425-433$.

(S2) Yoshioka, K.; Ando, D.; Watanabe, T. A comparative study of matrix- and nano-assisted laser 
desorption/ionization time of flight mass spectrometry of isolated and synthetic lignin. Phytochem. Anal. 2011, 23 (3), 248-253.

(S3)Nishiwaki-Akine, Y.; Watanabe, T. Dissolution of wood in $\alpha$-keto acid and aldehydic carboxylic acids and fractionation at room temperature. Green Chem. 2014, 16 (7), 3569-3579. 